\title{
Erratum to: Thermodynamic modeling of critical properties of ferroelectric superlattices in nano-scale
}

\author{
Yue Zheng • C.H. Woo
}

Received: 17 February 2009 / Accepted: 23 April 2009 / Published online: 2 December 2009

(C) Springer-Verlag 2009

Erratum to: Appl Phys A (2009) 97: 617-626

DOI 10.1007/s00339-009-5261-8

Equation (8) contains a typographical error. The correct equation is

$\chi^{\mathrm{T}}=\chi+\chi_{\mathrm{b}}= \begin{cases}\frac{\varepsilon_{0} C_{0}}{2\left|T-T_{\mathrm{c}}\right|}+\chi_{\mathrm{b}}, & \text { for } T<T_{\mathrm{c}}, \\ \frac{\varepsilon_{0} C_{0}}{\left|T-T_{\mathrm{c}}\right|}+\chi_{\mathrm{b}}, & \text { for } T>T_{\mathrm{c}} .\end{cases}$
Note that this typographical error does not affect any results in the paper [1].

\section{References}

1. Y. Zheng, C.H. Woo, Appl. Phys. A 97, 617 (2009)

The online version of the original article can be found under doi:10.1007/s00339-009-5261-8.

Y. Zheng · C.H. Woo $(\bowtie)$

Department of Electronic and Information Engineering,

The Hong Kong Polytechnic University, Hong Kong,

Hong Kong SAR, China

e-mail: chung.woo@polyu.edu.hk

Fax: +852-2-3654703

Y. Zheng

e-mail: yuezheng@hit.edu.cn 